\title{
Women's attitudes towards receiving family planning services from community health workers in rural Western Kenya.
}

\author{
Pamela A. Juma, Namuunda Mutombo, Carol Mukiira
}

African Population and Health Research center.

\begin{abstract}
Background: Kenya ranks among the countries in Africa with high fertility rates. In order to reverse the trends in high fertility rates, there is need to increase uptake of family planning services particularly by use of community health workers (CHWs) in providing these services in rural areas.

Objective: To describe the perceptions of women towards family planning service provision by CHWs in four rural districts of Western Kenya. It is based on baseline survey data from a three-year, rural community-based family planning project funded by The David and Lucile Packard Foundation.

Methods: A cross-sectional baseline survey was conducted in Western Kenya. The data presented is part of a broader the broader survey. A survey questionnaire was administered to 1,997 women (15-49 years) but only 963 cases were valid for our analyses.

Results: The findings revealed that only a third of the respondents exhibited high approval for Family Planning services from CHWs. Only four out of the thirteen variables explored showed significance on attitudes towards family planning services from CHWs. These are age, level of education, knowledge about family planning benefits and districts.

Conclusion: Women's perception towards family planning services delivered by CHWs in Western region in Kenya is quite low. To improve the demand and supply for family planning services in this region, there is need to invest a substantial amount of effort into sensitization of women on the relevance of CHWs in providing family planning services.
\end{abstract}

Key words: Community health workers, Women, Family Planning, Attitude

DOI: http://dx.doi.org/10.4314/ahs.v15i1.22

\section{Introduction}

In African countries including Kenya, contraceptive use, fertility rates and other reproductive health indicators in rural areas lag behind urban areas ${ }^{1}$. Even though Kenya's fertility rate declined from 8.1 in 1978 to 4.6 in 2008, the figures are much higher in rural areas, 5.2 compared to an urban rate $^{2}$ of 2.9. The persistent high fertility rate has been attributed to many factors including inadequate provision of family planning services. To address these challenges, there is need to accelerate

\section{Corresponding author:}

Pamela A. Juma

African Population and Health Research Center

P.O. Box 10787-00100

Phone: +254724270532

Email: atienopam@yahoo.com/pjuma@aphrc.org family planning services particularly in rural areas where these services are not adequately provided. This would allow for, reduced unintended pregnancies (which accounts for more than $40 \%$ of pregnancies in the country and unsafe abortions (which results to about 2,600 deaths in Kenya annually), among other benefits ${ }^{3,4}$.

In order to effectively scale up family planning service provision to meet the current and future needs, an adequate number of trained health workers must be available. However, the shortage of health workers hinders family planning service provision especially in rural areas. Task shifting and sharing of family planning service provision with community health workers (CHWs) is a means of increasing family planning service utilization without adding excessive burden to the already seriously strained health sector ${ }^{5}$. Task shifting serves as a means to extend family planning services into communities where they are needed, thereby improving coverage and geographic equity of family planning services ${ }^{6,7}$. Thus many developing countries have developed policies and programs to support task shifting and sharing of health 
service provision with CHWs, including provision of family planning services in rural areas.

Experiences from some developing countries show that community based family planning services have been used successfully to deliver family planning methods including distribution of pills as well as injectable contraceptives $^{8}$. In many countries this has been achieved by training and equipping community based health workers who provide various methods of family planning including injectable methods ${ }^{8,9}$. For instance, Zambia implemented integrated community based family planning and reproductive health with nutrition, education and income generating activities with positive outcome in increasing contraceptive prevalence in rural areas ${ }^{9}$ Even though literature on uptake as well as methods used for family planning at community level in developing countries is available, literature on perceptions and attitudes of women towards the use of family planning services offered by CHWs is scarce.

In Kenya, $\mathrm{CHWs}$ play a big role in enhancing primary health care services including family planning services. The majority of CHWs in Kenya had been trained by non-governmental organizations (NGOs) in the context of primary health care from the early 80s. However, there has been minimal government support and recognition for $\mathrm{CHWs}$ leaving this mainly to NGOs. The commitment to improve community based health interventions was made with the establishment of the Community Strategy during the implementation of Strategic Plan 11 2005-2010 whose objective was to provide health care services for all life cohorts and socioeconomic groups at household and community level ${ }^{10}$. The community strategy places the CHWs as the first level of health care providers. Their main activities include health promotion, disease prevention and provision of basic health care services including Family Planning in the community. Further policy support for improving access to family planning was realized with the development of the National Reproductive Health Strategy (2009 - 2015) with an overall thrust of involving the communities in reversing the decline in the health status of Kenyans through initiation and implementation of life-cycle focused health actions at community level. The strategy aims at increasing coverage of reproductive health services including family planning, through changing attitudes and behaviors of families and indi- viduals around reproductive health issues. Following this there has been increased donor funding and program to support family planning initiatives both at facility and community levels.

This paper describes the perceptions of women towards family planning service provision by CHWs in four rural districts of Western Kenya. It is based on baseline survey data from a three-year, rural community-based family planning project funded by The David and Lucile Packard Foundation. The Community Based Family Planning Project

The Community Based Family Planning Project was demonstration initiative implemented in Bondo Siaya Teso and Busia Districts of Western region in Kenya These districts were chosen due to high fertility rates, low use of family planning, as well as practical criteria, such as current implementation of other complimentary projects in these districts. According to the 2009 Census figures for the four districts, the total target population was about 1.4 million men and women of reproductive age. The project which was funded by $\mathrm{Da}$ vid and Lucile Packard Foundation was implemented by a consortium led by APHRC, with other partners in the consortium including Family Health Option of Kenya (FHOK), Great Lakes University of Kisumu (GLUK), Marie Stopes Kenya (MSK). The project aimed at increasing the contraceptive prevalence rates, reverse the stall in fertility levels, and reduce unwanted and mistimed pregnancies, levels of unsafe abortions, and maternal and infant mortality rates. The main focus of the project wasprovision of family planning services through community health workers. As part of its objective to expand the knowledge base of, and evidence on, community-based family planning project, a baseline survey, in which this study is based, was conducted in 2010, among women age 15-49. The survey sought to generate data to inform the design of the community based FP project and provide baseline information for evaluating the effectiveness of the intervention. The survey was designed to assess knowledge and use of contraception, availability and accessibility of FP services at the community level, desired number of children, planning of pregnancies, women ability to make decisions and control selected resources, the sexual behavior and marriage practices, exposure to family planning messages, and opportunities of integrating FP services with delivery, child and maternal health servic- es in health facilities. The project selected and trained 375 CHWs who were attached to community units and linked to health facilities. All the selected CHWs had to have the ability to read and write, as they are also engaged in data collection activities, majority (67\%) had completed secondary level education. Twenty two percent were male and majority (84\%) were between the age of 15 and 49. The selection of CHWs was not limited to age to allow participation of older women "mothers in law" as they are very influential in decision making on FP matters. Majority of the CHWs are married $(90 \%)$. The CHWs are provided with a monthly stipend to facilitate their transport and The CHWs distibute pills and condoms at the munity and refer clients for long-term and permanent methods and other Reproductive services to health facilities. They also distribute Information Education and Communication materials and counsel clients on various other reproductive health issues.

\section{Methods}

\section{Data source and sample}

The data were collected through a cross-sectional household survey using a structured household questionnaire. The study population was women aged 1549. The household survey sample was drawn from the population residing in the rural areas of the four districts, namely, Bondo, Busia, Siaya and Teso. A representative sample of 2,125 households was drawn for the survey using the frame of the $2008 \mathrm{KNBS}$. A total of 60 rural enumeration areas were sampled and distributed proportionally among the four districts and a total of 1,997 women were interviewed through faceto-face interviews. This represents a response rate of 86 percent. More information about this survey has been published in a report by the APHRC ${ }^{18}$. However, the multivariate analyses only included 963 women (48\%) who provided valid responses on CHWs.

The study received ethical approval from the Kenya Medical Research Institute Ethics Review Board.

\section{Variables}

The dependent variable used to measure attitude in thi paper is "level of tolerance for family planning service from CHWs". This variable was constructed from three questions, which asked women whether they could acept family planning services from a CHW (see Table 2). Women who provided a "no" response to all the questions were coded " 0 " and were categorized as having low tolerance level. Women who provide a "yes" response to one question only were coded " 1 " and were categorized as having medium level tolerance for CHWs. The women who provide a "yes" response to two or all the three questions were coded " 2 " and were categorized as having high level tolerance for service from CHWs. The categorization of scores was based on relative scores as majority of respondents had low scores. The scores ranged between " 0 " and " 2 " $\mathrm{Pu}$ bMed with a median score of " 1 ".

Thirteen independent variables were employed in the regression model (see Table 4). Worth noting is that less than twenty of these women were unmarried; so marital status was excluded from the analytical models. Further, women of ethnicities other than Luhya, Luo and Teso were also excluded from the analyses as they were very few $(<30)$.

Level of knowledge about family planning benefits fo the child and the mother were constructed from responses to a series of questions about knowledge on the impacts of family planning for the child and the mother. Each correct response to these questions was assigned a code of 1 while each incorrect response was assigned a code of 0 . All respondents who scored 0 on all questions had the final score of 0 and were coded as having no knowledge or classified into the "none" category. All respondents who scored 1 out of 7 for impacts on the child and 1-3 out of 12 for impacts on the mother were coded as having "low" knowledge level. Scores 2-7 on the impacts for the child and score 4-12 on the impacts for the mother were coded as "high" knowledge categories. The categorization of scores was based on relative scores as majority of respondents had low scores.

\section{Data analysis}

We used the ordered logit in order to determine factors influencing attitudes towards receiving family planning services from CHWs among women (15-49) in Western Kenya. More information about ordinal regression has been explained in detail by others ${ }^{11,12}$. Ordinal re- 
gression depends upon the idea of the cumulative logit, $\mathrm{p} \leq 0.050$ ). Therefore, any coefficient with a $\mathrm{p}$-value which in turn relies on the idea of the cumulative prob- greater than 0.050 is not significant at the $95 \%$ confiability. The cumulative probability can be thought of dence interval.

as the probability that the ith individual is in the jth or higher category. This can be expressed as:

$\mathrm{Cij}=\operatorname{Pr}(\mathrm{yi} \leq \mathrm{j})=$

where:

$\mathrm{y}=$ dependent variable (Level of tolerance fo family planning services from $\mathrm{CHWs}$ ); and

$\mathrm{k}=$ values of $\mathrm{y}(1 ., 2 ., 3 ., \ldots \mathrm{n})$.

The cumulative probability above can be transformed into the cumulative ordered logit:

$\operatorname{Logit}(\mathrm{Cij})=\log [\mathrm{Cij} /(1-\mathrm{Cij})]$

$$
=\alpha \mathrm{ij}-\beta \mathrm{ij}
$$

where:

$\alpha j=$ logit of the odds of being equal to or less than category $j$ for the baseline group (also referred to as intercepts or cut-points); and

$\beta=$ the increase in the log-odds of being higher than category $j$ per one-unit increase in the independent variable.

A negative $\beta$ coefficient shows lower log-odds (or lower likelihood) of having lower than high tolerant attitudes towards receiving family planning services from $\mathrm{CHWs}$ (i.e. lower tolerant attitude than the reference category). On the other hand, a positive coefficient indicates higher log-odds (or higher likelihood) of having higher than low tolerant attitudes towards receiving family planning services from CHWs (i.e. higher tolerant attitude than the reference category). An independent or predictor variable is considered significant if its effect on the dependent variable (attitude towards CHW FP services) is statistically significant at the .95 confidence interval (i.e.

\section{Results}

\section{Description of the sample} interviewed were valid for the regression analyses and their characteristics are shown in Table 1. Most (84\%) women in this sample reported that they listened to the radio while less than one quarter $(23 \%)$ had access to television and 25 percent said they read a newspaper/ magazine. By age, majority (48\%) women were aged 25 39 years and the rest were aged 15-24 (31\%) and 40$49(21 \%)$. The frequency distributions in Table 1 also region of Kenya as more than half $(56 \%)$ the women reported having had four or more children ever born.

Luo women were the majority at 57 percent, followed by Luhya women who comprised a quarter of the entire sample size. Catholics were minority when compared to non-Catholics; 30 percent versus 70 percent, respectivey. Approximately 81 percent had not received education beyond primary education. Table 1 , however, also shows that majority $(68 \%)$ of these women reporting discussing family planning with their partner/husband even though approximately half of these women were not using a method of contraception at the time of the survey. Strikingly, majority of women who reported current use of contraception were using a long acting or permanent method of contraception. According to district, more than a third (37\%) of the women surveyed from Siaya District while the smallest sample was from Bondo District (19\%).

Majority of women had none or low level of knowledge about impacts of using family planning on the child as less than 40 percent of women were in the high level knowledge category. Table 1 also shows that level of knowledge about impacts of using family planning on he mother is higher than that exhibited for the impacts on the child.
Only 963 (48\%) women (15-49) out of the 1,997 women confirm other observations about high fertility in this
Table 1: Percentage distribution of women (15-49) included in the analysis by selected characteristics in Western Kenya.

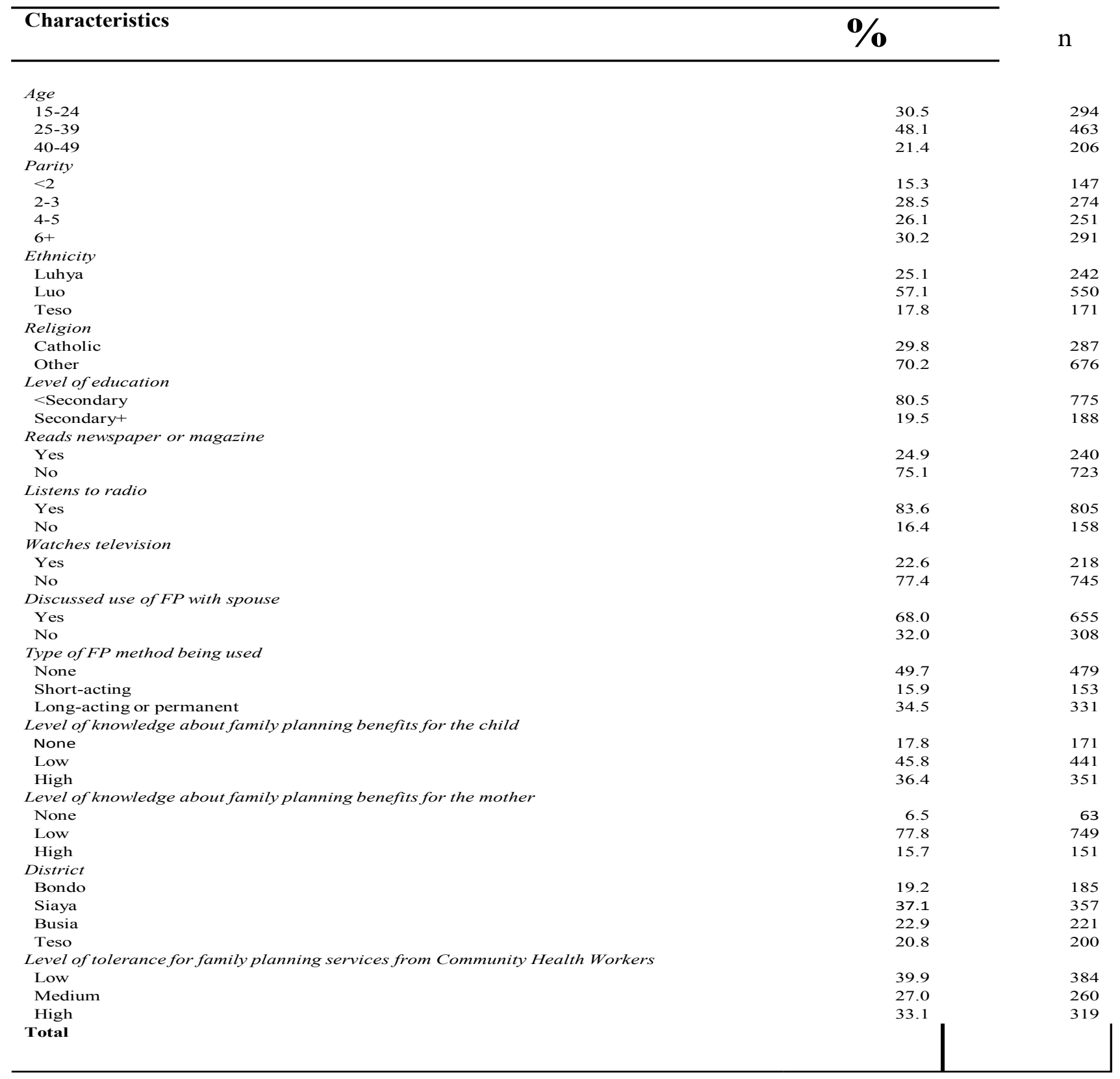

A third of the women show high acceptance or tol- lowed by the oral contraceptives. On the other hand, 40 erance for family planning services offered by CHWs. percent of the women said that they could not accept According to Table 2, the most accepted service from any of the three family planning services from a CHW. CHWs was the injectable contraceptive (Depo), fol-

Table 2. Per cent distribution of respondents' attitudes towards receiving family planning services from Community Health Workers in Western Kenya

\begin{tabular}{l|cccc}
\hline Questions & \multicolumn{4}{c}{ Responses } \\
\cline { 2 - 5 } & Yes & No & Don't Know & Missing \\
\hline $\begin{array}{l}\text { Q307. Community Health Workers are volunteers at the } \\
\text { village level who will be trained in many health areas. }\end{array}$ & 38.7 & 55.6 & 0.4 & 5.3 \\
$\begin{array}{l}\text { Would you accept the oral contraceptive pill from } \\
\text { Community Health Worker? }\end{array}$ & & & & \\
\hline $\begin{array}{l}\text { Q3308. Would you accept the emergency contraception } \\
\text { pill from a Community Health Worker? }\end{array}$ & 36.2 & 57.8 & 0.7 & 5.4 \\
\hline $\begin{array}{l}\text { Q309. Would you accept receiving an injectable (Depo) } \\
\text { from a Community Health Worker? }\end{array}$ & 43.9 & 49.9 & 0.7 & 5.6 \\
\hline
\end{tabular}


Factors associated with acceptance of family plan- type of family planning method being used and level A third of women had high level of tolerance for family mother and district. Middle aged women (25-39) have planning services from CHWs while approximately 40 the highest (35\%) acceptance of family planning serpercent of the women did not want to receive these vices from CHWs followed by young women (15-24). services from CHWs. Table 3 shows some significant By parity, women with less than two children have the associations between level of tolerance for family plan- lowest acceptance of services from CHWs while those ning services from CHWs and some characteristics. with 2-3 children showed the highest approval for famThe strongest associations are observed for age, parity, ily planning from the community workers.

Table 3: Percent distribution of respondents by level of tolerance for family planning services from CHWs in Western Kenya.

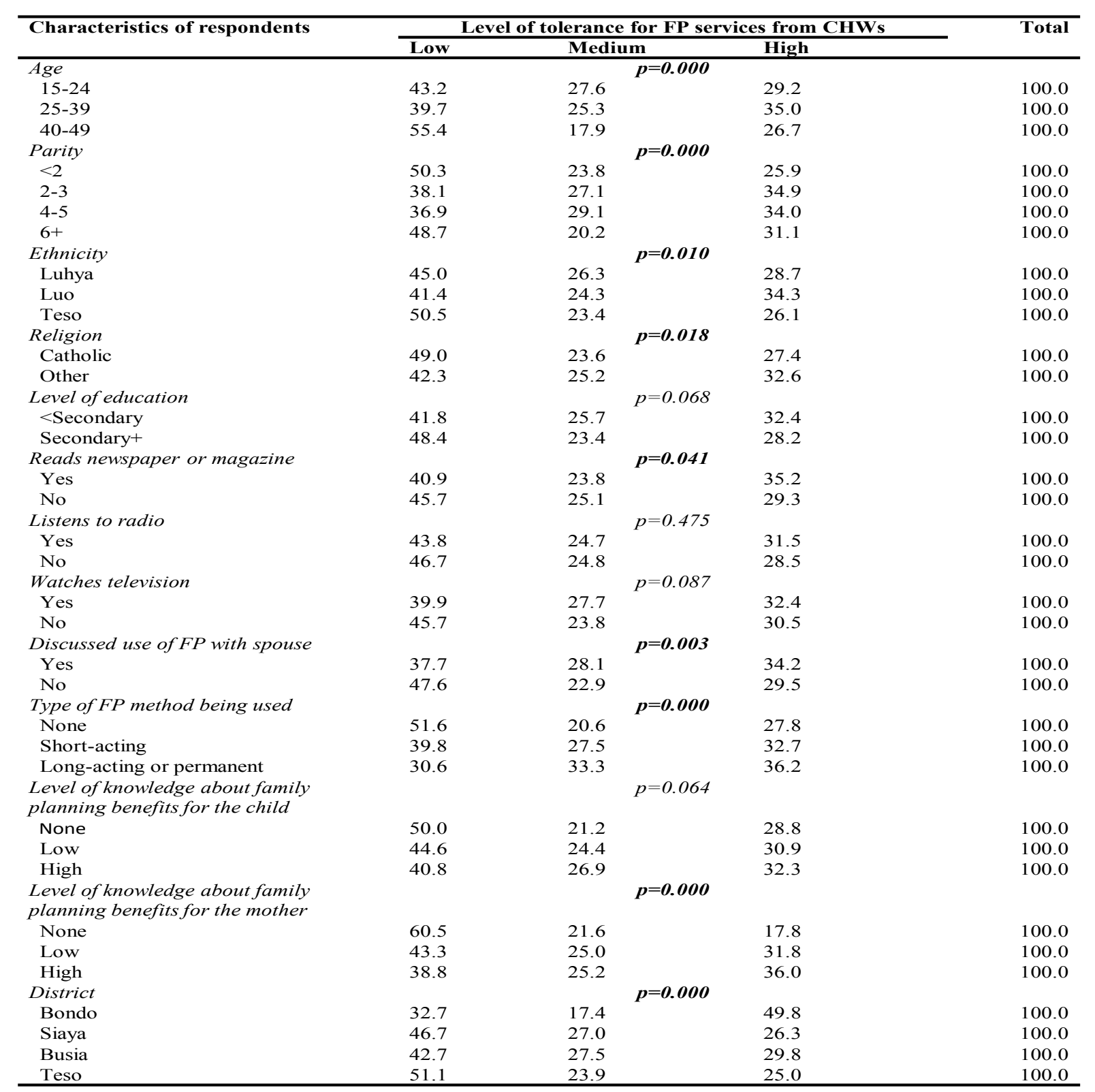

Women who reported not using a method of contra- the mother was also directly correlated with tolerance ception at the time of the survey also showed the lowest for family planning services from CHWs i.e. the higher approval level for family planning services from CHWs the level of knowledge about benefits of using family while women on long-acting methods of contraception planning for the mother, the higher the level of accepthad the highest acceptance for services from CHWs. ance for family planning services from CHWs. AccordKnowledge about the benefits of family planning for ing to district, women from Bondo district exhibited the highest $(50 \%)$ approval for family planning services, Predictors of attitudes towards family planning followed by their counterparts from Busia $(30 \%)$ while only a quarter of women from Teso had high acceptance of family planning services from CHWs.

\section{ervices from CHWs}

Table 4 shows that of all the variables included in the multivariate model, only four variables are of significance on attitudes towards family planning services Other significant associations were observed for eth- from CHWs. These variables are age, level of educanicity, religion, reading a newspaper or magazine and tion, level of knowledge about family planning benefits discussion of family planning use with partner/hus- for the mother and district. Young women (15-24) are band. According to ethnicity, Luo women had the high- more likely to approve of family planning services from est (34\%) approval for services from CHWs, followed CHWs than older women (40-49). Middle aged womby the Luhya women (29\%). By religion, non-Catholics en (25-39) also exhibit higher log-odds of having more showed higher acceptance of family planning services than less tolerant attitudes towards family planning serfrom CHWs than the Catholic women. Women who vices from CHWs than older women but the difference read a newspaper or magazines also exhibited higher is not significant. Table 4 also shows that education is approval for services from CHWs than those who did the strongest predictor of attitudes towards services not read a newspaper or magazine. Table 3 also shows from CHWs in our model. Women with low education that women who discussed family planning use with (i.e. less than secondary level) are more likely to accept partner/husband had higher tolerance for services family planning services from CHWs than the more edfrom CHWs than women who did not discuss family ucated women (i.e. higher than primary level). planning with their partner/husband.

Table 4. Log-odds of having more than less tolerant attitudes towards receiving family planning services from CHWs in Western Kenya among women (15-49) by selected characteristics.

\begin{tabular}{|c|c|c|c|}
\hline Characteristics of respondents & $\bar{B}$ & $\overline{p \text {-value }}$ & $\mathbf{n}$ \\
\hline Age & & & \\
\hline 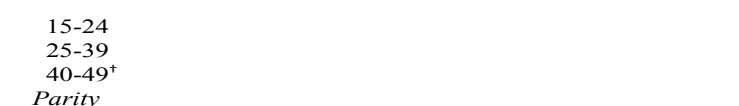 & $\begin{array}{l}0.571 \\
0.282\end{array}$ & $\begin{array}{l}\mathbf{0 . 0 1 4} \\
0.101\end{array}$ & $\begin{array}{l}294 \\
463 \\
206\end{array}$ \\
\hline $\begin{array}{l}<2 \\
2-3 \\
2-3\end{array}$ & $\begin{array}{l}-0.197 \\
-0.165 \\
0.164\end{array}$ & $\begin{array}{l}0.423 \\
0.407 \\
0.75\end{array}$ & $\begin{array}{l}147 \\
274 \\
251\end{array}$ \\
\hline $4-5$ & - & - & 291 \\
\hline 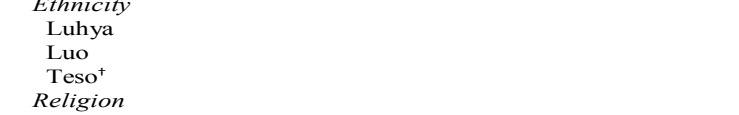 & $\begin{array}{l}-0.090 \\
-0.051\end{array}$ & $\begin{array}{l}0.735 \\
0.875\end{array}$ & $\begin{array}{l}\begin{array}{l}242 \\
550 \\
171\end{array} \\
\end{array}$ \\
\hline $\begin{array}{l}\text { Catholic } \\
\text { Othert }\end{array}$ & -0.080 & 0.556 & $\begin{array}{l}287 \\
676\end{array}$ \\
\hline $\begin{array}{l}\text { Level of education } \\
\text { - Secondary } \\
\text { Secondary }+\end{array}$ & 0.524 & 0.002 & $\begin{array}{l}775 \\
188\end{array}$ \\
\hline $\begin{array}{l}\text { Reads newspaper or magazine } \\
\text { Yes } \\
\mathrm{No}^{+}\end{array}$ & 0.148 & 0.345 & $\begin{array}{l}240 \\
723\end{array}$ \\
\hline $\begin{array}{l}\text { Listens to radio } \\
\text { Yes } \\
\text { Not }\end{array}$ & -0.078 & 0.647 & $\begin{array}{l}805 \\
158\end{array}$ \\
\hline $\begin{array}{l}\text { Watches television } \\
\text { Yes } \\
\text { No+ }\end{array}$ & 0.072 & 0.644 & $\begin{array}{l}218 \\
745\end{array}$ \\
\hline $\begin{array}{l}\text { Discussed use of FP with spouse } \\
\text { Yes } \\
\text { No+ }\end{array}$ & 0.203 & 0.146 & $\begin{array}{l}655 \\
308\end{array}$ \\
\hline 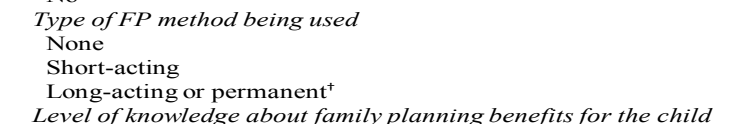 & $\begin{array}{l}-0.214 \\
-0.174\end{array}$ & $\begin{array}{l}0.138 \\
0.347\end{array}$ & 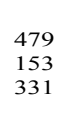 \\
\hline $\begin{array}{l}\text { Level of knowledge about family planning benefits for the child } \\
\text { None } \\
\text { Lou } \\
\text { Hight }\end{array}$ & $\begin{array}{c}0.281 \\
-0.130\end{array} \longrightarrow$ & $\begin{array}{l}0.201 \\
0.279\end{array}$ & $\begin{array}{l}171 \\
441 \\
351\end{array}$ \\
\hline $\begin{array}{l}\text { Level of knowledge about family planning benefits for the mother } \\
\text { None } \\
\text { Low } \\
\text { High+ }\end{array}$ & $\begin{array}{l}-0.713 \\
-0.097\end{array}$ & $\begin{array}{l}\mathbf{0 . 0 4 9} \\
0.609\end{array}$ & $\begin{array}{r}63 \\
749 \\
151\end{array}$ \\
\hline $\begin{array}{c}\text { Hight } \\
\begin{array}{c}\text { District } \\
\text { Bondo }\end{array}\end{array}$ & & & \\
\hline $\begin{array}{c}\text { Bondo } \\
\text { Siaya } \\
\text { Busia } \\
\text { Tusion }\end{array}$ & $\begin{array}{l}0.842 \\
0.029 \\
0.265\end{array}$ & 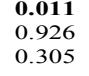 & $\begin{array}{l}185 \\
357 \\
221\end{array}$ \\
\hline 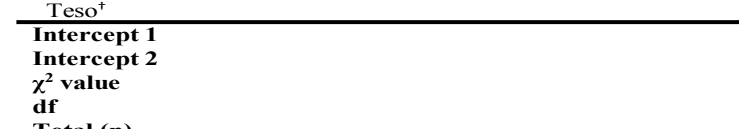 & $\begin{array}{l}0.260 \\
\text { 1.4.426 } \\
5.389 \\
222\end{array}$ & $\begin{array}{l}0.434 \\
\substack{0.300 \\
0.000} \\
-=0\end{array}$ & 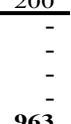 \\
\hline Total (n) & & & 963 \\
\hline
\end{tabular}


According to district, women from Bondo, Siaya and Busia were more likely to accept services from CHW than their counterparts from Teso. However, only women from Bondo district had significantly higher log-odds of having more than less tolerant attitudes family planning services from CHWs than women from Teso district. Level of knowledge about family planning benefits for the mother also shows women without any knowledge about the benefits of using family planning for the mother have a lower likelihood of accepting family planning services from CHWs than women with high knowledge. Though women with low knowledge of family planning benefits for the mother are less likely to accept services from CHWs than women with high knowledge, data also reveal that the difference between the two categories of women is statistically not significant.

\section{Discussion}

Results from this survey demonstrated that only a third $(33 \%)$ of women in Western Kenya have high approval for family planning services from CHWs. Furthermore, only four out of the thirteen variables explored showed significance on attitudes towards family planning services from CHWs. These are age, level of education, level of knowledge about family planning benefits for the mother and district. Young women (15-24) are more likely to approve of family planning services from CHWs than older women (40-49), while there is no significant difference between middle aged women (2539) and the older women. The result depicts some age pattern to resistance to use of family planning services offered by CHWs For many years provision of family planning methods has been done by trained health professionals at the health facility level, hence older women may find it more difficult to accept that this cadre of health workers could be trusted to administer family planning services at community level than young women. Another reason could be because older women do not utilize family planning services in general.

Education is also a very critical factor in understanding attitudes of women towards family planning services offered by CHWs in Western Kenya. The less educated women had higher approval for the services offered by CHWs than the more educated. Education is a facto at is theoretically associated with many aspects of human behaviour including health seeking behaviour. In his case, it might appear that since the more educated are more likely to be enlightened about some health is sues, they are also more likely to question the quality of family planning service provision by CHWs as compared to those provided by highly trained health professionals. This coincides with existing literature that has shown that women value highly qualified health professionals for family planning services ${ }^{13}$. For women in the rural areas to approve of services offered by CHWs it would require that mechanism be put in place to ensure quality of services delivery by CHWs and to sensitize he communities about this.

Our paper also demonstrates that women who do not know the benefits of family planning for the mother have lower approval for services from CHWs. This is expected as an individual may only approve of an intervention if it is perceived to be beneficial and also because knowledge shapes attitude. Client education on benefits and methods of family planning has been known to lead to better access and utilization of servic$\mathrm{es}^{14}$. This has been achieved in the past through community awareness interventions such as health education and media approaches. Women who read newspaper tended to know benefits of family planning, thus has higher approval for family planning services offered by CHWs. Newspapers and other media sources are known to be major channels for communicating family planning information. Using these channels is particularly important in addressing barriers to family planning services utilization including fears, misconceptions and myths about side effects of family planning methods.

Women from Bondo, Siaya and Busia districts exhibited higher approval for the community based family planning services offered by CHWs compared with women from Teso district but only women from Bondo district had a statistically significant difference from their counterparts in Teso district. This could due to the fact that Bondo district has a longer history of community-based health services including community based distribution of family planning commodities. So the experience with CHWs in providing services in this district seems to be facilitating this high level of confidence in CHWs to provide family planning services.
The findings from this survey indicate that approval for family planning services delivered by CHWs is quite low as only a third of the respondents exhibited high approval for services from community health workers. Therefore, there is need to invest a substantial amoun of effort into sensitization of women on the relevance of CHWs in providing family planning services. To enhance the uptake of the family planning project in Western Kenya, mechanisms for awareness creation on family planning services provided by CHWs should be put in place. General community sensitization activities through community forums as well as utilization of existing media channels would enhance this awareness. In addition awareness creation through community leaders and through men would enhance knowledge and acceptance of family planning by women in these rural districts. This should also be accompanied by government legitimation of CHWs particularly by approving their role in provision of family planning services, as well as enhancing their capacity to provide quality family planning services to communities. Given the ongoing scale up of the community strategy, there is need to give more attention to building the capacity of $\mathrm{CHW}$ to provide quality family planning services. Enhancing capacity of CHWs to providefamily planning service would help reduce the unmet need for family planning in the area and further impact on overall fertility rate reduction in the country.

\section{Acknowledgement}

The baseline survey from which the study data was drawn was implemented by African Population and Health Research Center (APHRC) and Great Lakes University of Kisumu in collaboration with Marie Stopes Kenya and the Family Health options Kenya. The authors thank Jean-Christophe Fotso, Dr. Gwen Morgan, Mr. Paul Kuria formerly of the APHRC, Prof Richard Muga, Dr. Alex Ezeh, Dr. Chima Izugbara, Ms. Sherine Athero and Mr. James Aringo for their contributions at different levels to the Western Kenya community-based Family Planning project and for making possible to have the data that was used in this paper.

We acknowledge the David and Lucile Packard Found tion who funded the community-based family planning project.
. Foreit J, Raifman S. Increasing Access to Family Planning (FP) and Reproductive Health (RH) Services Through Task-Sharing between Community Health Workers (CHWs) and Community Mid-Level Professionals in Large-Scale Public-sector Programs: a Literture Review to Help Guide Case Studies. Population Council 2011

2. Kenya National Bureau of Statistics (KNBS), ICF Macro. Kenya Demographic and Health Survey 200809. Calverton, Maryland: KNBS and ICF Macro 2010.

3. Rutstein SO. Effects of preceding birth intervals on neonatal, infant, and under-five years mortality and nutritional status in developing countries: evidence from the demographic and health surveys. International Journal of Gynecology and Obstetrics. 2005;89(Suppl 1):S7-S24.

4. Conde-Agudelo A, Balizan JM. Maternalmorbidity and mortality associated with interpregnancy interval: cross sectional study. . BMJ. 2000;321:1255-9.

5. Schneider H, Hlophe H, Van Rensburg D. Community health workers and the response to HIV/AIDS in South Africa: tensions and prospects. Health Policy Planning. 2008;23:179-87.

World Health Organization. Task shifting to tackle health worker shortage. Geneva: World Health Organization 2007

7. Zachariah R, Ford N, Philips M, S.Lynch, Massaquoi M, Janssens V, et al. Task shifting in HIV/AIDS: opportunities, challenges and proposed actions for sub-Saharan Africa. Transactions of the Royal Society of Tropical Medicine and Hygiene, 2009;103:549-58.

8. Hoke TH, Wheeler SB, Lynd K, Green MS, Haimalala B, Razafindravony, et al. Community-Based provision of injectable contraceptives in Madgaska: 'task shifting' to expand access to injectable contracepives. Health Policy and Planning. 2012;27(1):52-9.

9. White JS, Speizer IS. Can family planning outreach bridge the urban-rural divide inZambia? BMC Health Services Research. 2007;7:143-1517.

10. Ministry of Health. Kenya national health sector strategic Plan II (NHSSP II) 2005-2010. Reversing the Trend. Nairobi: Ministry of Health., 2005

11. Allison P. Comparing Logit and Probit Coefficients Across Groups. Sociological Methods and Research. 1999;28(2):186-208.

2. Hosmer D, Lemeshow S. Applied Logistic Regression. Second ed. New York: John Wiley \& Sons; 2000. 13. Azmat SK, Mustafa G, Hameed W, Ali M, Ahmed 
A, Bilgrami M. Barriers and perceptions regarding different contraceptives and family planning practices amongst men and women of reproductive age in rural Pakistan: A qualitative study. Pakistan Journal of Public Health. 2012;2(1):1-8.

14. Majlessi F, Banaem L, Sharia M. Cleint and health workers perceptions of Family Planning services. Iranian Red Crescent Medical Journal. 2011;13(7):469-74.

15. Naanyu, V. Baliddawa J, Peca E, Karfakis J, Nyagoha N Koeach B, An examination of postpartum family planning in western Kenya: "I want to use contraception but I have not been told how to do so". African
Journal of Reproductive Health, 2013; 17(3):44-53.

16. Diamond-Smith, N., Campbell M, Madan, S., Misinformation and fear of side effects of family planning. Culture Health and Sexuality, 2012; 14(4), . 421-433.

17. Hindin, MJ, McGough, LJ, Adanu, RM Misperceptions, misinformation and myths about modern contraceptive use in Ghana. Journal of Family Planning and Reproductive Health Care, 2014; 40(1), 30-35.

18. APHRC, Rural community -Based Family Planning Project of Western Kenya: Demonstration Phase, 2009-2012, Report on Baseline Survey, Nairobi Kenya, 2013 